\title{
The Dependence of the CZK Exchange Rate on the Development of the GDP in the Czech Republic in the Conditions of an Expected Crisis
}

\author{
Veronika Machová1,*, and Tomáš Krulický \\ ${ }^{1}$ Institute of Technology and Business in Ceske Budejovice, School of Expertness and Valuation, \\ Okruzni 517/10, 37001 Ceske Budejovice, Czech Republic \\ ${ }^{2}$ University of Zilina, Faculty of Operation and Economics of Transport and Communications, \\ Department of Economics, Univerzitna 1, 01026 Zilina, Slovakia
}

\begin{abstract}
.
Research background: In the past, some studies proved that the development of a currency exchange rate predicts the development of the whole national economy. The monetary market overtakes the development of the actual economy for a few months. Does this apply also in the case of the Czech koruna, in the era of the global Coronavirus pandemics and in the world affected by the pandemics?

Purpose of the article: The main objective is to analyze a dependence of the Czech koruna (CZK) to Euro (EUR) exchange rate development on gross domestic product of the Czech Republic in the conditions of an expected crisis.

Methods: The data used of the analysis are represented by the information about the CZK and EUR exchange rate from the beginning of 1999 to the 15 th June 2020 and by the quarterly development of the Czech GDP. To measure the dependence and predict the development of the GDP based on the CZK exchange rate development, the method of AI is used, namely the regression analysis using the artificial neural networks.

Findings \& Value added: The effect of EUR/CZK on GDP can be quantified reaching around $31 \%$. It is assumed that the GDP will fall significantly in 2020 with a certain growth only being possibly expected in 2021 (even more significantly in the second quarter of 2021). Due to the GDP development, the development of the EUR/CZK could then be forecasted as well.
\end{abstract}

Keywords: exchange rate; GDP; national economy; artificial neural networks

JEL Classification: $C 45 ; E 27 ; F 31$

\footnotetext{
*Corresponding author: machova@mail.vstecb.cz
} 


\section{Introduction and literature research}

The currency value development has a fundamental effect on gross domestic product (GDP). This relationship can be explained by an example of a particular economy, specifically the economy of the Czech Republic. In 2013, due to a crisis situation, the Central Bank (the Czech National Bank) began to implement an expansionary monetary policy, which a priori aimed to start the national economy. The manifestation of this monetary activist policy was the devaluation of the Czech koruna (CZK) on the currency market, which the CNB further supported by interventions on the currency market. Thus, the CNB Board fulfilled their second objective, i.e. to strengthen exports. This means a traditional view in relation to the exchange rate, exports, and the resulting domestic product [1]. In the current strong trend of new computing technologies, the use of cybernetic models may seem desirable and necessary. It is important to mention that the COVID-19 epidemic significantly affected the prediction models. The possibility of a later reflection of epidemics in the results analysis of these systems cannot be ruled out. This precedent raises a promise of more valuable predictions, as the systems will be taught a new variable.

The outbreak of the COVID-19 coronavirus pandemic has a very significant negative short-term impact on global financial markets, and at the same time calls for effective measures. Specifically, members of the Visegrad Group noted a significant correlation between the growth in the number of the infected and the depreciation of national currencies [2-3]. In this context, Aslam, Mohti and Ferreira [4] call for a clear comprehensive response from the policy makers. The media had a negative impact on market developments during the peak of the epidemic. Based on the information they published, the principle of rational expectation prevailed among investors [5]. A bitter advantage of COVID-19 is the predictive potential that reduces the exchange rate volatility associated with the occurrence of local outbreaks [6]. Habib and Stracca [7] examine the stability of national currencies. They find that the most stable are the currencies of large states, which are less open to the inflow of foreign capital. A positive current account, which is a part of the balance of payments, tends to increase the pressure on the domestic currency [8]. The effect of the savings of migrants on the exchange rate is also interesting. Based on the examined data in the years 1966-2014 in Canada, remarkable results were achieved - we can talk about a long-term relationship between migration and currency appreciation [9].

Antonyova et al. [10] classify the benefits of measuring the gross domestic product (GDP). They state that GDP reflects the economic development of the country. Marilos, Rodousakis and Soklis [11] evaluate the aforementioned COVID-19 epidemic impact on the overall development of Greece's GDP. With the decrease in tourism revenues in the range between EUR 3.5 and 10.5 billion, there would be an overall decline in GDP of $2.1 \%$ to $6 \%$. That is a perceptible deficit. The GDP growth is currently influenced significantly by the capital growth and the mobility of human capital. Such situation is caused by globalization. A very bad environmental impact remains its downside [12]. Song et al. [13] also confirm the negative impact of the economic development on the environment. Damborsky [14] brings an interesting finding. He examines the impact of foreign direct investment on the regions of the Czech Republic. He confirmed the hypothesis that the investment recipients are the more developed regions with a higher ratio of GDP to total GDP. This widens the gap between the developed and the less developed regions. Finally, Axelrad, Sabbath and Hawkins [15] also give interesting insights. From a sample of thirteen countries, including the Czech Republic, they are looking for links between body BMI, alcohol consumption, depression, overall health, and GDP. The results show an indirect relationship between the decline in GDP and the aforementioned health issues.

Currently, neural networks are very popular as a quality prediction model. Their use is quite complex in all spheres. They use the principles of biological learning patterns, thus 
achieving very positive results [16]. Vochozka, Horak and Suler [17] also talk about a relevant output of the neural network prediction model in economic sectors. Vochozka et al. [18] classify positively a neural network prediction model for its ability to give excellent statistical performance compared to conventional models. Specifically, self-learning skills, independence, adaptation, and fault tolerance make neural networks the first choice in predicting complicated economic phenomena. These include, for example, economic growth, the development of exchange rates, the development of GDP, the development of stock indices and commodities, etc. [19-21]. Neural networks can even predict the potential viability of a company [22]. In conclusion, the application of neural networks can provide important guidance in implementing effective monetary and fiscal policies.

\section{Data and methods}

The paper's main objective is to analyze a dependence of the Czech koruna (CZK) to Euro (EUR) exchange rate development on gross domestic product of the Czech Republic between the 1st quarter of 1999 and the 1st quarter of 2020. The partial objectives are as follows:

1. To determine the dependence of the CZK to EUR exchange rate (hereinafter referred to as "EUR/CZK") on development of the Czech Republic's gross domestic product (hereinafter referred to as "GDP") in the period under review.

2. To forecast development of the EUR/CZK in individual quarters until the end of 2021 based on the relation to GDP.

Regarding the basic economic theory courses, students learn that there is a mutual relationship between GDP and a currency value. It is yet apparent that the value is not only determined by the amount of GDP realized. The following research question may therefore be formulated: Is it possible to quantify the effect of the Czech Republic's GDP on the CZK currency value?

\subsection{Data}

A specific analysis will include data on the EUR/CZ exchange rate development related each time to the last day of a quarter in the given period (the first quarter of 1999 - the first quarter of 2020). The data are publicly available on the Czech Statistical Office website. The second time series will involve GDP in the same period with the data also being publicly available on the website.

As may be seen from the figure, the exchange rate of the target variable, i.e. EUR/CZK, decreases over time. At the beginning of the period under review, it amounts to almost 39 CZK per Euro, then reaches its lowest value in mid-2008, i.e. approximately 24 CZK per EUR. At the end of 2019, the rate stands at around $25 \mathrm{CZK}$, whilst rising to more than 27 CZK in the first quarter of 2020. On the contrary, the GDP development has a growing trend throughout the period. In the first quarter of 1999, it reached almost 600,000 million CZK with its highest value being realized in 2019. Not only the overall trend of the time series, but also its seasonal fluctuations are certainly interesting. The curve indicates that each season (or each quarter) is characterized by a specific increase or decrease in the GDP.

\subsection{Methods}

In order to examine the aforementioned dependence, it will be necessary to take into account other variables as well (besides the target EUR/CZK exchange rate and the GDP input variable). When specifying the main objective, it may be found out how EUR/CZK develops over time and also how the result affects GDP. Thus, the interdependence between time 
(expressed by a certain year and quarter) and GDP on the one hand and EUR/CZK on the other will be observed. First, a regression model is to be developed. Subsequently, shares of individual variables in the resulting forecast will be examined through sensitivity analysis.

Furthermore, there will be regression performed using neural structures in the TIBCO Statistica software version 13. Multilayer perceptron networks (MLP) and radial basis function neural networks (RBF) will be generated with EUR/CZK being the dependent variable. To be able to come to a conclusion and fulfill the main objective, it is necessary to work with two sets of independent variables:

1. The first set will include Year and Month (representing time) and GDP. All are continuous variables.

2. The second set will only include GDP.

The datasets are to be randomly divided into three sub-data sets - training, testing and validation. The first group will contain $70 \%$ of the input data. Based on the training set, neural structures will be generated. The two remaining sets shall always be left with $15 \%$ of the input information. Both groups will be used to verify reliability of the found neural structures. Basic statistics of the sub-data sets are given in Table 1.

Table 1. Basic statistics of monitored time series EUR/CZK, GDP.

\begin{tabular}{|l|r|r|}
\hline \multicolumn{1}{|c|}{ Basic statistics by samples } & Input: GDP (mil. CZK) & Target: EUR/CZK \\
\hline Minimum (Train) & 563,117 & 24.34500 \\
\hline Maximum (Train) & $1,488,148$ & 36.64000 \\
\hline Mean (Train) & 945,826 & 28.53377 \\
\hline Standard deviation (Train) & 230,626 & 3.42110 \\
\hline Minimum (Test) & 573,883 & 23.89500 \\
\hline Maximum (Test) & $1,412,299$ & 35.65000 \\
\hline Mean (Test) & $1,078,367$ & 27.05500 \\
\hline Standard deviation (Test) & 266,461 & 3.27450 \\
\hline Minimum (Validation) & 503,674 & 24.66500 \\
\hline Maximum (Validation) & $1,410,427$ & 38.42000 \\
\hline Mean (Validation) & 905,583 & 29.38917 \\
\hline Standard deviation (Validation) & 324,270 & 6.33640 \\
\hline Minimum (Overall) & 503,674 & 23.89500 \\
\hline Maximum (Overall) & $1,488,148$ & 38.42000 \\
\hline Mean (Overall) & 958,856 & 28.44576 \\
\hline Standard deviation (Overall) & 243,318 & 3.52624 \\
\hline There will be 1O0,000 & & \\
\hline
\end{tabular}

There will be 100,000 neural networks generated, and 5 artificial neural networks showing the best characteristics will be retained. In the hidden MLP layer, the first set of independent variables will involve 2 to 12 neurons in the hidden layer. As for the RBF, there will always be at least 21 (and always up to 30 ) neurons in the hidden layer. In relation to a single multilayer perceptron network, the following distribution functions in the hidden layer and in the output layer shall be considered: Linear, Logistics, Atanh, Exponential, Sinus.

Other settings will remain default (according to an ANS tool - automated neural network). If necessary, weights of individual neurons will be iterated using a VNS tool (own neural network). However, it should be noted that any improvement of ANS is uncertain, as it is rather an iteration. Subsequently, sensitivity analysis will be conducted. That will answer the question of how substantial the potential effect of GDP is on the amount of EUR/CZK.

The second part of the task is to forecast possible future development of the EUR/CZK exchange rate. However, that requires a forecast of the GDP development, which will be done using Wolfram's Mathematica software version 12. Artificial neural networks will also be used together with the "Predict" tool. The tool uses neural networks as one of the possible 
methods. In addition, a neural network consists of stacked layers, each performing a simple computation. Information is processed layer by layer from the input layer to the output layer. The neural network is trained to minimize a loss function on the training set using gradient descent. Finally, there will be a comparison of the results obtained using the first set and the second set of independent variables.

\section{Results}

\subsection{Balanced time series}

An overview of the most successful, and hence preserved, neural networks is given in Table 2.

Table 2. Overview of preserved neural networks.

\begin{tabular}{|c|c|c|c|c|c|c|c|c|c|c|c|}
\hline Index & Net. name & $\begin{array}{c}\text { Training } \\
\text { perf. }\end{array}$ & $\begin{array}{c}\text { Test } \\
\text { perf. }\end{array}$ & $\begin{array}{c}\text { Validation } \\
\text { perf. }\end{array}$ & $\begin{array}{c}\text { Training } \\
\text { error }\end{array}$ & $\begin{array}{c}\text { Test } \\
\text { error }\end{array}$ & $\begin{array}{c}\text { Validation } \\
\text { error }\end{array}$ & $\begin{array}{c}\text { Training } \\
\text { agorithm }\end{array}$ & $\begin{array}{c}\text { Error } \\
\text { function }\end{array}$ & $\begin{array}{c}\text { Hidden } \\
\text { activation }\end{array}$ & $\begin{array}{c}\text { Output } \\
\text { activation }\end{array}$ \\
\hline 1 & $\begin{array}{c}\text { MLP } \\
3-7-1\end{array}$ & 0,984135 & 0,953106 & 0,969580 & 0,181806 & 0,750054 & 0,589743 & $\begin{array}{c}\text { BFGS } \\
105\end{array}$ & SOS & Logistic & Identity \\
\hline 2 & $\begin{array}{c}\text { MLP } \\
3-6-1\end{array}$ & 0,984331 & 0,965149 & 0,971680 & 0,179223 & 0,525956 & 0,499160 & $\begin{array}{c}\text { BFGS } \\
252\end{array}$ & SOS & Tanh & Exponent. \\
\hline 3 & $\begin{array}{c}\text { MLP } \\
3-7-1\end{array}$ & 0,981684 & 0,945346 & 0,969435 & 0,209306 & 0,605815 & 0,490468 & $\begin{array}{c}\text { BFGS } \\
142\end{array}$ & SOS & Logistic & Logistic \\
\hline 4 & $\begin{array}{c}\text { MLP } \\
3-9-1\end{array}$ & 0,988177 & 0,981906 & 0,973761 & 0,135330 & 0,281696 & 0,433730 & $\begin{array}{c}\text { BFGS } \\
262\end{array}$ & SOS & Logistic & Tanh \\
\hline 5 & $\begin{array}{c}\text { MLP } \\
3-5-1\end{array}$ & 0,986210 & 0,976763 & 0,971113 & 0,161002 & 0,431364 & 0,474225 & $\begin{array}{c}\text { BFGS } \\
211\end{array}$ & SOS & Tanh & Identity \\
\hline
\end{tabular}

The above table indicates excellent results of neural networks. The performance of all sub-data sets expressed by a correlation coefficient is very high reading a value of almost 0.95 and higher in all cases. In general, the search is for a network whose correlation coefficient is approximately the same and simultaneously as high as possible in all three sets. All preserved neural networks show almost identical performance characteristics and errors in all sub-data sets. The Broyden-Fletcher-Goldfarb-Shanno algorithm was used for the calculations, whilst the least squares method was used as an error function. To activate the inner layer of neurons, neural networks use a logistics function or a hyperbolic tangent function. Furthermore, identical, exponential, logistics and hyperbolic tangent functions are used for the output neuron activation. To be able to state which of the preserved neural networks will suit the forecast the most, basic statistical characteristics of balanced EUR/CZK time series will be assessed (for more details, see Table 3).

Table 3. Basic statistical characteristics of balanced time series according to individual sub-data sets.

\begin{tabular}{|l|c|r|r|r|r|}
\hline \multicolumn{1}{|c|}{ Statistics } & \multicolumn{1}{|c|}{$\mathbf{1 . M L P}$} & $\mathbf{2 . M L P}$ & $\mathbf{3 . M L P}$ & $\mathbf{4 . M L P}$ & $\mathbf{5 . M L P}$ \\
& $\mathbf{3 - 7 - 1}$ & $\mathbf{3 - 6 - 1}$ & $\mathbf{3 - 7 - 1}$ & $\mathbf{3 - 9 - 1}$ & $\mathbf{3 - 5 - 1}$ \\
\hline Minimum prediction (Train) & 24.96991 & 25.13507 & 25.10512 & 24.78663 & 24.71323 \\
\hline Maximum prediction (Train) & 37.03565 & 36.64403 & 36.52705 & 36.17819 & 36.87655 \\
\hline Minimum prediction (Test) & 25.05532 & 25.34296 & 25.35904 & 23.92133 & 24.96902 \\
\hline Maximum prediction (Test) & 36.97057 & 36.21590 & 36.49892 & 36.24443 & 36.67780 \\
\hline Minimum prediction (Validation) & 26.31489 & 26.15978 & 25.74334 & 24.43127 & 26.08419 \\
\hline Maximum prediction (Validation) & 38.67207 & 38.01590 & 36.63447 & 36.30061 & 37.72994 \\
\hline Minimum residual (Train) & -1.69429 & -1.43364 & -1.35126 & -1.17859 & -1.36072 \\
\hline Maximum residual (Train) & 1.45776 & 1.68938 & 1.77356 & 1.44208 & 1.56219 \\
\hline Minimum residual (Test) & -2.93733 & -2.65568 & -2.64923 & -1.43717 & -2.39320 \\
\hline Maximum residual (Test) & 0.83201 & 0.80529 & 1.32172 & 0.53111 & 0.14178 \\
\hline Minimum residual (Validation) & -2.29521 & -2.27290 & -1.53119 & -1.59862 & -2.26408 \\
\hline Maximum residual (Validation) & 1.01376 & 0.79007 & 1.78553 & 2.11939 & 0.98859 \\
\hline
\end{tabular}




\begin{tabular}{|l|r|r|r|r|r|}
\hline Minimum standard residual (Train) & -3.97359 & -3.38644 & -2.95357 & -3.20382 & -3.39120 \\
\hline Maximum standard residual (Train) & 3.41887 & 3.99053 & 3.87664 & 3.92007 & 3.89330 \\
\hline Minimum standard residual (Test) & -3.39161 & -3.66185 & -3.40369 & -2.70781 & -3.64382 \\
\hline Maximum standard residual (Test) & 0.96069 & 1.11040 & 1.69812 & 1.00068 & 0.21588 \\
\hline Minimum standard residual (Validation) & -2.98876 & -3.21706 & -2.18637 & -2.42737 & -3.28776 \\
\hline Maximum standard residual (Validation) & 1.32009 & 1.11826 & 2.54954 & 3.21812 & 1.43556 \\
\hline
\end{tabular}

It is obvious from the table that the characteristics of balanced time series according to the preserved neural networks and individual sub-data sets differ to a minimum extent. More noticeable deviations can be observed in relation to the residues. Nevertheless, it is appropriate to include all preserved neural networks in further calculations.

In order to determine whether EUR/CZK is dependent on GDP and to what extent, sensitivity analysis was carried out (Table 4).

Table 4. Sensitivity analysis of EUR/CZK on GDP.

\begin{tabular}{|l|r|r|r|r|}
\hline \multicolumn{1}{|c|}{ Networks } & GDP (mil. CZK) & \multicolumn{1}{c|}{ Year } & Quarter & Share of GDP on generating (EUR/CZK) \\
\hline 1.MLP 3-7-1 & $9.990928 \mathrm{E}+00$ & 20.6442 & 1.212224 & $31 \%$ \\
\hline 2.MLP 3-6-1 & $1.733305 \mathrm{E}+09$ & 47.5038 & 8.208120 & $100 \%$ \\
\hline 3.MLP 3-7-1 & $3.239170 \mathrm{E}+01$ & 21.0863 & 1.740924 & $59 \%$ \\
\hline 4.MLP 3-9-1 & $3.216034 \mathrm{E}+02$ & 120.5903 & 3.606025 & $72 \%$ \\
\hline 5.MLP 3-5-1 & $9.810282 \mathrm{E}+00$ & 17.9809 & 1.122955 & $34 \%$ \\
\hline Average & $3.466611 \mathrm{E}+08$ & 45.5611 & 3.178050 & $31 \%$ \\
\hline
\end{tabular}

The table clearly shows that the effect of GDP on the EUR/CZK exchange rate development is relatively significant. However, the interval depends on a particular neural network model used ranging from $31 \%$ to $100 \%$. Thus, in view of the conclusions to be beneficial, it is essential to determine (validate) which neural network model is the most appropriate.

\subsection{Validation of neural network models}

To perform validation, it was necessary to forecast future GDP developments. That was done in accordance with the Mathematica software methodology. Forecast characteristics are shown in Figure 1.



Fig. 1. GDP forecast characteristics. 
The above figure illustrates the basic characteristics of a model and its training (creation) process. As already mentioned in the Methods section, neural networks were used. Moreover, standard deviation, number of examples, dose size, loss and training time are also given. Particular values of the GDP forecast are stated in Table 5.

Table 5. GDP forecasts until the end of 2021.

\begin{tabular}{|r|r|}
\hline Date & GDP in mil. CZK \\
\hline 30.06 .2020 & $1,261,875$ \\
\hline 30.09 .2020 & $1,171,936$ \\
\hline 31.12 .2020 & $1,239,259$ \\
\hline 31.03 .2020 & $1,227,217$ \\
\hline 30.06 .2021 & $1,328,879$ \\
\hline 30.09 .2021 & $1,282,118$ \\
\hline 31.12 .2021 & $1,305,633$ \\
\hline
\end{tabular}

In relation to the entire GDP time series development to be evident, including the values forecasted until the end of 2021, a graph representing the period under review was created (Figure 2).

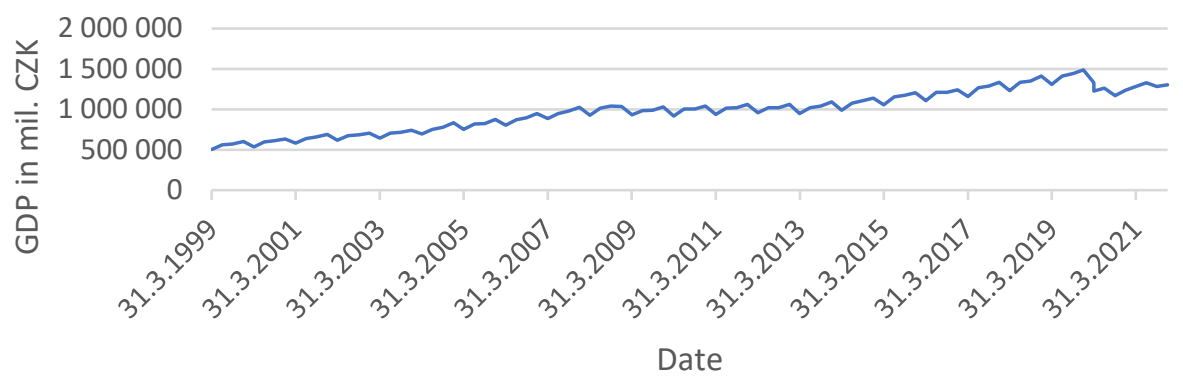

Fig. 2. GDP development including forecasts until the end of 2021.

As captured in the graph, there is a significant GDP decline in the second quarter of 2020 (as opposed to the expected seasonal growth). That may be the result of measures against COVID-19.

Consequently, all data are now available to forecast the future development of EUR/CZK. It may therefore be proceeded to forecasts according to individual preserved neural networks. Based on the result, it will be determined which set of the independent data helped to create a higher quality model (Figure 3).
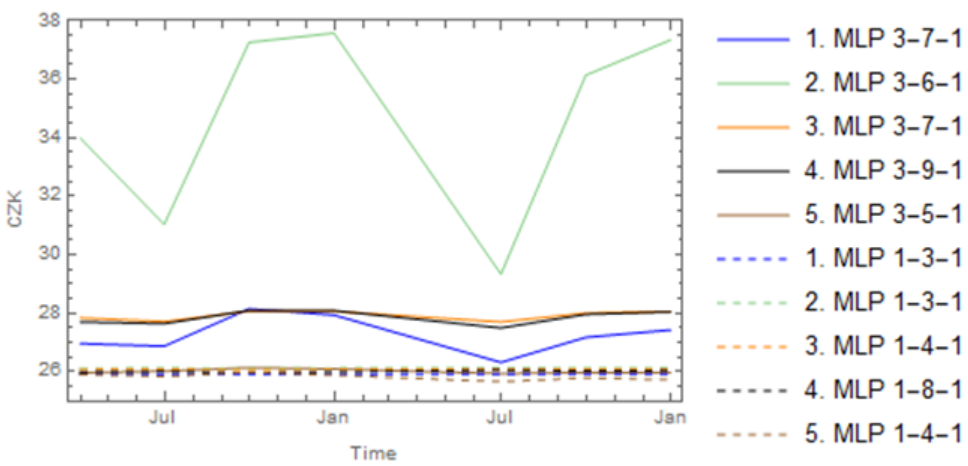

Fig. 3. Forecasts of future EUR/CZK development until the end of 2021. 
The solid lines represent forecasts in which GDP plays a significant role, whereas the dashed lines represent forecasts based only on GDP. Hence the above figure validates the previously mentioned partial conclusion, i.e. the EUR/CZK exchange rate development depends to some extent on GDP. Correspondingly, what may be excluded are forecasts using models developed on the basis of the second set of independent variables and simultaneously using the neural network 2. MLP 3-6-1. In the following part, the main focus will therefore only be on neural networks developed on the basis of the first set of independent variables (yet to be complete, 2. MLP 3-6-1 shall also be included).

\subsection{Neural networks of the first set of independent variables}

Balanced time series using artificial neural networks and their forecasts were illustrated graphically. The success of individual models in balancing the time series as well as the future forecasts until the end of 2021 is registered. The dependence, or forecasted dependence, of EUR/CZK on GDP, or GDP forecast were also illustrated graphically.

There appears to be probable development according to networks 1. MLP 1-7-1, 3. MLP 1-7-1 and 4. MLP 1-9-1. A decline in GDP is expected, followed by an increase in EUR/CZK. Rather an expert estimate may be used to state the most likely development according to 1 . MLP 1-7-1, which then implies that the above research question may be answered. Yes, the EUR/CZK exchange rate is dependent on GDP development. The effect can be quantified amounting to $31 \%$ in this case (or from the first quarter of 1999 to the first quarter of 2020).

\section{Conclusion}

The main objective was to analyze a dependence of the Czech koruna (CZK) to Euro (EUR) exchange rate development on gross domestic product of the Czech Republic related to the period from the 1st quarter of 1999 to the 1 st quarter of 2020. The partial objectives were as follows:

1. To determine the dependence of the CZK to EUR exchange rate (hereinafter referred to as "EUR/CZK") on development of the Czech Republic's gross domestic product (hereinafter referred to as "GDP") in the period under review.

2. To forecast development of the EUR/CZK in individual quarters until the end of 2021 based on the relation to GDP.

The main objective was fulfilled as the experiment proved that the effect of EUR/CZK on GDP can be quantified reaching around $31 \%$. That was subsequently verified by forecasting the future EUR/CZK development. It is assumed that the GDP will fall significantly in 2020 with a certain growth only being possibly expected in 2021 (even more significantly in the second quarter of 2021). Due to the GDP development, the development of the EUR/CZK could then be forecasted as well. The results show that the CZK exchange rate will weaken to more than $28 \mathrm{CZK}$ per EUR in the observed period indicating that the CZK exchange rate will therefore be more in favor of the Czech Republic's exports abroad. The most favorable situation for exporters (yet the worst for importers) will then occur in the third quarter of 2020.

To be able to determine the very exact value of the EUR/CZK dependence on the Czech Republic's GDP, all of the effects involved would have to be recognized, which is almost impossible to do. In further research, other possible influences and their relationship to the EUR/CZK will gradually be identified leading to a more accurate result of the relationship between the GDP and the EUR/CZK. 


\section{References}

1. Mandel, M., Tran, Q. V. (2017). An Empirical Verification of Export Function Focused on the Impact of EUR/CZK Exchange Rate. Politicka ekonomie, 65(6), 649-668.

2. Czech, K., Wielechovski, M., Kotyza, P., Benesova, I., Laputkova, A. (2020). Shaking Stability: COVID-19 Impact on the Visegrad Group Countries' Financial Markets. Sustainability, 12(5).

3. He, Q., Liu, J. Y., Wang, J. Y., Wang, S. Z., Yu, J. S. (2020). The impact of COVID-19 on stock markets. Economic and Political Studies, 8(3), 257-288.

4. Aslam, F., Mohti, W., Ferreira, P. (2020). Evidence of Intraday Multifractality in European Stock Markets during the Recent Coronavirus (COVID-19) Outbreak. International Journal of Financial Studies, 8(2), Article Number 31.

5. Engelhardt, N., Krause, M., Neukirchen, D., Posch, P. (2020). What Drives Stocks during the Corona-Crash? News Attention vs. Rational Expectation. Sustainability, 12(12).

6. Iyke, B. N. (2020). The Disease Outbreak Channel of Exchange Rate Return Predictability: Evidence from COVID-19. Emerging Markets Finance and Trade, 56(10), 2277-2297.

7. Habib, M. M., Stracca, L. (2012). Getting beyond carry trade: What makes a safe haven currency? Journal of International Economics, 87(1).

8. Hashimoto, O., Ono, Y. (2020). A simple aggregate demand analysis with dynamic optimization in a small open economy. Economic Modelling, 91, 89-99.

9. Aziz, N., Cooray, A., Teo, W. L. (2020). Do immigrants' funds affect the exchange rate? The World Economy.

10. Antonyova, A., Antony, P., Soewito, B., Bin Abdullah, A., Nagapan, S. (2018). Reflection of Gross Domestic Product into the Income Values According to the Attained Level of Education in Europe. Advanced Science Letters, 24(12), 9261-9265.

11. Mariolis, T., Rodousakis, N., Soklis, G. (2020). The COVID-19 multiplier effects of tourism on the Greek economy. Tourism Economics, Article Number 1354816620946547.

12. De Pascale, G., Sardaro, R., Faccilongo, N., Conto, F. (2020). What is the influence of FDI and international people flows on environment and growth in OECD countries? A panel study. Environmental Impact Assessment Review, 84.

13. Song, W. Z., Wang, C., Chen, W. Q., Zhang, X. L., Li, H. R., Li, J. (2020). Unlocking the spatial heterogeneous relationship between Per Capita GDP and nearby air quality using bivariate local indicator of spatial association. Resources, Conservation and Recycling, 160, Article Number 104880.

14. Damborsky, M. (2019). Regional distribution of the foreign direct investments in the context of the economic level of the regions of the Czech Republic. Geographia Cassoviensis, 13(2), 161-179.

15. Axelrad, H., Sabbath, E. L., Hawkins, S. S. (2017). The impact of the 2008 recession on the health of older workers: data from 13 European countries. The European Journal of Public Health, 27(4), 647-652.

16. Vrbka, J., Rowland, Z. (2017). Stock price development forecasting using neural networks. In Váchal, J., Vochozka, M., Horak, J. (Eds.), SHS Web of Conferences: Innovative Economic Symposium 2017 - Strategic Partnership in International Trade. Les Ulis, France: EDP Sciences. 
17. Vochozka, M., Horak, J., Suler, P. (2019). Equalizing Seasonal Time Series Using Artificial Neural Networks in Predicting the Euro-Yuan Exchange Rate. Journal of Risk and Financial Management, 12(2).

18. Vochozka, M., Rowland, Z., Suler, P., Marousek, J. (2020). The influence of the international price of oil on the value of the EUR/USD exchange rate. Journal of Competitiveness, 12(2), 167-190.

19. Feng, L. H., Zhang, J. Z. (2020). Application of artificial neural networks in tendency forecasting of economic growth. Economic Modelling, 40, 76-80.

20. Stehel, V., Horak, J., Vochozka, M. (2019). Prediction of institutional sector development and analysis of enterprises active in agriculture. E+M Ekonomie a Management, 22(4), 103-118.

21. Vrbka, J., Nica, E., Podhorska, I. (2019). The application of Kohonen networks for identification of leaders in the trade sector in Czechia. Equilibrium- Quarterly Journal of Economics and Economic Policy, 14(4).

22. Horak, J., Vrbka, J., Suler, P. (2020). Support Vector Machine Methods and Artificial Neural Networks Used for the Development of Bankruptcy Prediction Models and their Comparison. Journal of Risk and Financial Management, 13(3). 